\title{
Pattern of asthma medication use among children from a large urban center in Brazil
}

\author{
Djanilson Barbosa Santos • Alvaro A. Cruz • Silvia de Magalhães Simões • \\ Laura C. Rodrigues • Paulo Augusto Moreira Camargos • \\ Helena Lutescia Luna Coelho • Mauricio L. Barreto
}

Received: 10 May 2011 / Accepted: 14 June 2011 / Published online: 30 June 2011

(C) Springer-Verlag 2011

\begin{abstract}
Purpose Despite the advances in asthma therapeutics, there are few data on the use and determinants of anti-asthmatic drugs in the general population of children. This study describes the use of asthma medications among children in the general population and in children with current asthma, living in a large urban center in Brazil.

Methods A population-based cross-sectional survey, aimed at analyzing asthma determinants, was conducted with 1,382 children aged 4-11 years, between February and May 2006, in Salvador, Brazil. At baseline, an extensive questionnaire was applied, including questions about the use of asthma medications in the last 12 months.
\end{abstract}

P. Camargos is supported by the Brazilian research agencies CNPq Conselho Nacional de Desenvolvimento Científico e Tecnológico(Grant 303827/2009-2), and FAPEMIG- Fundação de Amparo à Pesquisa do Estado de Minas Gerais (Grant PPM-00230-10). These research agencies had no influence in study design; in the collection, analysis, and interpretation of data; in the writing of the report; or in the decision to submit the paper for publication.

D. B. Santos

Centro de Ciências da Saúde,

Federal University of Recôncavo da Bahia,

Santo Antônio de Jesus, Bahia, Brazil

A. A. Cruz

ProAR, Faculdade de Medicina da Bahia,

Federal University of Bahia,

Salvador, Brazil

S. de Magalhães Simões

School of Medicine, Federal University of Sergipe,

Aracaju, Brazil

L. C. Rodrigues

London School of Hygiene \& Tropical Medicine,

London, UK
Results In all studied children $(n=1,382)$ aged $4-11$ years, oral beta2-agonists were the drugs most frequently used (9.8\%), followed by short-acting inhaled beta2-agonists $(4.3 \%)$ and systemic corticosteroids (1.6\%). Antiasthmatic drug use was higher among males than females, and it significantly decreased with age in both genders. A total of 312 children $(22.6 \%)$ reported current asthma, and $62 \%$ of them were not being treated with any antiasthmatic drugs. Of all those who reported following a certain type of treatment, $20 \%$ used oral beta2-agonists alone; $6.1 \%$, short-acting inhaled beta2-agonists alone; and $4.8 \%$, a combination of both drugs. Anti-asthmatic drug use did not differ according to socioeconomic status,

\footnotetext{
P. A. M. Camargos

Health Sciences Postgraduate Program,

Federal University of São João del-Rei,

Minas Gerais, Brazil

D. B. Santos $\cdot$ H. L. L. Coelho

Department of Pharmacy, Federal University of Ceará,

Fortaleza, Brazil

D. B. Santos • M. L. Barreto

Instituto de Saúde Coletiva, Federal University of Bahia,

Salvador, Brazil

D. B. Santos $(\triangle)$

Center for Health Sciences,

Federal University of Recôncavo da Bahia,

Av. Carlos Amaral, 1015 - Cajueiro,

Santo Antônio de Jesus, BA, Brazil 44570-000

e-mail: dejab@bol.com.br
} 
except for the use of inhaled beta2-agonists and systemic corticosteroids.

Conclusions An overwhelming majority of asthmatic children were not using long-term medications for asthma, in particular inhaled corticosteroids, regardless of the severity of their disease. This result points to the deficiencies of the Brazilian public health system in recognizing this important pharmacological need for child care and thereby limiting the access of these children to a group of efficacious, available, and low risk therapeutic medications.

Keywords Asthma Pharmacoepidemiology $\cdot$ Asthma . Therapy $\cdot$ Children $\cdot$ Prevalence $\cdot$ Cross-sectional studies . Brazil

\section{Introduction}

Asthma is a chronic disease, very frequent in children and adolescents, and its prevalence has increased in recent decades, although with significant differences among countries [1, 2]. Despite therapeutic advances achieved in the last decades, asthma continues to be an important public health problem, and it requires a substantial use of health services [1-3]. Among the factors influencing the elevated morbidity of asthma, the following stand out: genetic predisposition, environmental factors, lifestyle, under-diagnosis, and ineffective treatment, including inadequate management of the disease and the adoption of outdated therapeutic practices $[4,5]$.

Current international and national guidelines, directives, and consensus recognize that asthma is an inflammatory disease and that inhaled corticosteroids are the most effective therapy available, as they have a prolonged action and have been available for over 30 years. However, recent studies in different populations have shown the under-use of this class of drugs and the great use of other classes of drugs, the shortacting $\beta$-agonists $[6-8]$. Therapy based on the preferred use of these $\beta$-agonists results in inadequate control of asthma and may be contributing to a greater number of asthmarelated deaths [9]. In the United States, there is evidence that morbidity and mortality from asthma have increased in children who live in unfavorable socioeconomic conditions [10]. One of the probable explanations is that asthma, when treated only during exacerbations with drugs that are effective, yet short-acting, increases the frequency of visits to emergency rooms and the risk of death [11, 12]. Prevalence of asthma in children in Latin America, especially in Brazil, is high $[2,6,13]$.

Standard population surveys have been used as the main instrument to estimate the prevalence of asthma in the population [14]. In children aged 6-7 years and 1314 years, living in five Brazilian regions, prevalence of wheezing in the last 12 months ranged from 24.3 to $19.0 \%$ [15]. Rosário Filho reported an increase in spending on drugs for asthma treatment and in hospitalizations due to this disease [16]. Other studies performed in children with asthma in the public health care facilities in Brazil revealed small proportions of use of anti-inflammatory treatment, ranging from 6.0 to $14.0 \%[17,18]$. In Brazil, the lack of population-based studies on the use of anti-asthmatics in children, as well as on the reasons for this lack, necessitates such studies, particularly as the use of these drugs is considered an indirect indicator of quality of care provided to asthmatic children. Thus, the objectives of this study were (1) to determine the pattern of consumption of antiasthmatic drugs and (2) to analyze factors associated with the patterns found, in children living in poorer areas of an urban center of northeastern Brazil.

\section{Methods}

Study design and population

A population-based cross-sectional study was performed in a cohort of children in the urban area of the city of Salvador (northeastern Brazil) between February and May 2006. The methods of the longitudinal study are described in detail elsewhere [19]. In brief, the sample was selected randomly from 24 areas, representative of the population living in areas of Salvador that had no sanitation at the time of the cohort recruitment. The original sample had 1,445 children. This is a cross-sectional study of these children, and 1,382 had complete data to participate in this specific analysis.

\section{Data collection}

A structured pre-coded questionnaire was used. It included a specific component on the use of medications for respiratory diseases, and another, involving demographic and socioeconomic variables, health conditions and questions about asthma-related symptoms based on the Brazilian Portuguese version of the International Study of Allergies and Asthma in Children (ISAAC) Questionnaire [14]. Table 1 gives further details of the questions used in this study. This instrument was submitted to a pre-pilot evaluation to test the comprehensibility of the questions. After the necessary corrections were made, a pilot study was performed with $10 \%$ of the source population for the final test of the questionnaire, development of the manual of instructions, and training of interviewers. Questionnaires were applied using home interviews, conducted with the mothers or adults responsible for the children. In case of absence of interviewees or refusal, interviewers would return to these homes at least two more times. 
Table 1 Questions on asthma medication use and other factors together with the answer alternatives presented to children from a large urban center in Brazil

\begin{tabular}{|c|c|}
\hline Administered questions & Answer alternatives \\
\hline \multicolumn{2}{|l|}{ Health conditions } \\
\hline In general, how has the health of your child been in the last 15 days? & Excellent, very good, good, poor, very poor \\
\hline \multicolumn{2}{|l|}{ Exposure to cigarette smoke } \\
\hline Does your child's mother smoke cigarettes? & No, yes \\
\hline Are there other people living in the house who smoke cigarettes, including parents? & No, yes \\
\hline \multicolumn{2}{|l|}{ Questions on wheezing and asthma } \\
\hline Has your child ever had wheezing or whistling in the chest at any time in the past? & No, yes \\
\hline Has your child had wheezing or whistling in the chest in the last 12 months? & No, yes \\
\hline How many attacks of wheezing has your child had in the last 12 months? & None, $1-3,4-12$, more than 12 \\
\hline $\begin{array}{l}\text { In the last } 12 \text { months, how often, on average, has your child's sleep been disturbed due } \\
\text { to wheezing? }\end{array}$ & $\begin{array}{l}\text { Never woken with wheezing, less than one night per } \\
\text { week, one or more nights per week }\end{array}$ \\
\hline $\begin{array}{l}\text { In the last } 12 \text { months, has wheezing ever been severe enough to limit your child's } \\
\text { speech to only one or two words at a time between breaths? }\end{array}$ & No, yes \\
\hline Has your child ever had asthma? & No, yes \\
\hline In the last 12 months, has your child's chest sounded wheezy during or after exercise? & No, yes \\
\hline $\begin{array}{l}\text { In the last } 12 \text { months, has your child had a dry cough at night, apart from a cough } \\
\text { associated with a cold or chest infection? } \\
\text { Asthma management }\end{array}$ & No, yes \\
\hline $\begin{array}{l}\text { In the last } 12 \text { months, has your child used any medicines, pills, puffers, or other } \\
\text { medication for wheezing or asthma? }\end{array}$ & No, yes \\
\hline Medicines & If you answered "yes," please name the medication(s) \\
\hline How often? & $\begin{array}{l}\text { When wheezy; regularly (i.e., every day for at least } \\
2 \text { months of the year) }\end{array}$ \\
\hline \multicolumn{2}{|l|}{$\begin{array}{l}\text { In the past } 12 \text { months, how many visits has your child made to any of the following } \\
\text { health professionals for wheezing or asthma? }\end{array}$} \\
\hline Doctor & None, $1-3,4-12,>12$ \\
\hline Hospital emergency department & None, $1-3,4-12,>12$ \\
\hline $\begin{array}{l}\text { In the past } 12 \text { months, how many times has your child been admitted to hospital } \\
\text { because of wheezing or asthma? }\end{array}$ & None, $1,2,>2$ \\
\hline
\end{tabular}

\section{Asthma definition}

Asthma was defined as the occurrence of wheezing in the 12 months preceding the application of the questionnaire, associated with at least one of the following criteria: diagnosis of asthma some time in life, at least four episodes of wheezing in the chest in the last year, history of wheezing in the chest during or after physical exercises, or having woken up at least one night per week due to wheezing in the last 12 months. Children who met these criteria and had taken $\beta$-agonists daily or reported their use during hospitalizations due to acute asthma in the last 12 months comprised the group classified with the diagnosis of severe asthma.

\section{Asthma medication use}

The use of asthma medication in the 12 months preceding the interview was measured by answering the following question: "In the last 12 months, did your child use any medication (pills, syrups, nebulizers, or pressurized metered dose inhalers) for wheezing, whistling, or asthma?" Based on the responses to these questions, the medicines for asthma taken by children and reported by mothers were classified as follows: (1) quick-relief medications to treat acute symptoms and exacerbations (short-acting $\beta$-agonists, ipratropium bromide, and systemic corticosteroids) and (2) long-term control medications or "controllers" (inhaled corticosteroids, prolonged-release theophylline, long-acting ß-agonists, systemic corticosteroids, and antileukotrienes).

\section{Covariables}

A total of five sets of variables were considered: demographic, socioeconomic, health conditions, life habits, and severity of asthma. The following were considered as socioeconomic and demographic variables: child's age and sex; mother's age, ethnicity (white or black), and level of 
education; and monthly household income $(<1,1-2,3-5 \times$ minimum wage). The national minimum wage at the time of the survey corresponded to US\$100. Child health conditions (excellent/very good, good, poor/very poor) were established by the mother's self-perception of health. Exposure to cigarette smoke was defined by current maternal smoking (yes/no) and presence of other smokers in the household (yes/no). Information about the severity of asthma in the last 12 months consisted of the number of episodes of wheezing (none, $1-3$, and $\geq 4$ ); frequency of awakenings at night due to wheezing (has never woken up with wheezing, less than one night per week, one or more nights per week); difficulty in pronouncing two consecutive words during exacerbations (yes/no); perception of wheezing during or after exercising (yes/no); visits to the doctor while having exacerbations (none, $1-3, \geq 4$ times); visits to emergency services due to exacerbations (none, one or more times) and hospitalizations due to asthma (none, one or more times).

\section{Data analysis}

Prevalence of asthma medication use according to sex and age group was calculated by the proportion of children who had taken at least one of these medicines in the last 12 months, divided by the total number of children in each age group per sex. In the bivariate analysis, chi-squared test was used to compare proportions (Mantel-Haenszel) and the linear trend test for ordinal variables. In the present study, analysis was performed by comparing children who had used asthma medication with those who had taken other types of medicines or not, according to maternal information. A $P$ value $<0.05$ was considered significant. Data analysis was performed using Stata software, version 9.0 (StataCorp, College Station, TX).

\section{Ethical approval}

Approval was obtained from the Brazilian Research Ethics Committee. Written informed consent was obtained from the legal guardian of each child studied.

\section{Results}

The 1,382 children studied represent $95.6 \%$ of the cohort (1,445 individuals). Of all children, 63 were excluded from this analysis: 26 because they were not found as a result of change of address and 37 because complete information, provided by the mothers and obtained in previous survey, was not available. Of the 1,382 studied children, $12.3 \%$ had taken asthma medication specifically (R03) and 219 children (15.8\%) had taken medicines for respiratory problems in the last 12 months, as reported by their mothers. The use of medication for asthma was similar between boys and girls, at 13 and $12 \%$, respectively. The prevalence of use of medicines decreased significantly with age $(P<0.001)$ in both sexes; in the extremes of age groups into which the study population was categorized, 4-5 and 9-11 years, the prevalence decreased from 17.2 to $8.0 \%$ in females $(P=0.005)$ and from 20.3 to $8.8 \%$ in males $(P=0.001)$ (Table 2$)$.

Oral $\beta$-agonists as monotherapy were the therapeutic regimen most frequently reported by mothers, with inhaled B-agonists following far behind (Fig. 1). The oral B-agonists most frequently used in syrup formulation were salbutamol $(87.2 \%)$ and fenoterol $(9.5 \%)$, whose consumption was reported by 138 children, of which 88 (64\%) used them intermittently. Inhaled B-agonists were consumed by 59 children, of which $21(36 \%)$ did so on a daily basis. In contrast to the oral $\beta$-agonists, the inhaled $B$-agonist most frequently used was nebulized fenoterol (93.1\%). Systemic corticosteroids, especially prednisone and prednisolone, were used by $22(1.6 \%)$ children, of which $14(64 \%)$ used these intermittently (data not show).

Of the 312 children with asthma, 37.2\% had taken medications for asthma (R03) in the last 12 months. Medications for asthma were equally used by girls and boys, at 38 and $36 \%$, respectively (Table 2 ). The frequency of medication did not increase with age $(P=0.886)$. A perception of the child's health reported by the mother as being poorest was associated with greater consumption of medication $(P<0.001)$. With regard to the severity of asthma in the last 12 months, consumption of medication was greater in children with difficulty in pronouncing two consecutive complete words during exacerbations (52\%), those wheezing during or after exercising (46\%), and those who experienced one or more hospitalizations due to exacerbations of asthma in the last year $(51 \%)$. Oral $B$ agonist as monotherapy was the therapeutic regimen most frequently reported (19.9\%), followed by inhaled $\beta$-agonists (6.1\%), with 15 (4.8\%) children receiving both (Fig. 1). Oral ß-agonists (salbutamol and fenoterol were the most frequently used) were used by 91 children and, of these, 59 $(64.8 \%)$ consumed them intermittently. A total of 40 children reported the use of inhaled $\beta$-agonists, especially salbutamol and fenoterol, of which $16(40.0 \%)$ used daily. Systemic corticosteroids (especially prednisone and prednisolone) were used by $17(5.4 \%)$ children, of which $70.1 \%$ reported occasional use (data not show).

As shown in Table 3, the use of medication for asthma in children did not differ significantly according to monthly household income, except for the use of inhaled $\beta$-agonists and systemic corticosteroids, whose use was more frequent in children from families with a monthly income above the minimum wage. The use of oral $\beta$-agonists was signifi- 
Table 2 The number and percentage of children using asthma medication in a population-based sample from an urban center in Brazil in relation to social, environmental, demographic, and health characteristics

\begin{tabular}{|c|c|c|}
\hline Characteristics & $\begin{array}{l}\text { Children with } \\
\text { asthma }(n=312)\end{array}$ & $\begin{array}{l}\text { Total san } \\
\text { children }\end{array}$ \\
\hline $\begin{array}{l}\text { Total using any medication } \\
\text { for asthma } \\
\text { Demographics }\end{array}$ & $116(37)$ & $170(12)$ \\
\hline \multicolumn{3}{|l|}{ Age (years) } \\
\hline $4-5$ & $36(37)$ & $50(19)^{*}$ \\
\hline 6 & $27(38)$ & $41(13)$ \\
\hline $7-8$ & $31(35)$ & $50(11)$ \\
\hline $9-11$ & $22(42)$ & $29(8)$ \\
\hline \multicolumn{3}{|l|}{ Sex } \\
\hline Male & $62(36)$ & $94(13)$ \\
\hline Female & $54(38)$ & $76(12)$ \\
\hline \multicolumn{3}{|l|}{ Socioeconomic } \\
\hline \multicolumn{3}{|l|}{ Maternal ethnicity } \\
\hline White & $12(44)$ & $19(14)$ \\
\hline Black & $104(36)$ & $151(12)$ \\
\hline \multicolumn{3}{|c|}{ Monthly household income (minimum wages) } \\
\hline$<1 \times \mathrm{MW}$ & $65(37)$ & $95(13)$ \\
\hline $1-2 \times \mathrm{MW}$ & $33(38)$ & $46(11)$ \\
\hline $3-5 \times \mathrm{MW}$ & $18(37)$ & $29(12)$ \\
\hline \multicolumn{3}{|c|}{ Maternal level of education (years) } \\
\hline $0-4$ & $29(36)$ & 39 (13) \\
\hline $5-8$ & $37(40)$ & $53(12)$ \\
\hline 9 or more & $49(36)$ & $76(12)$ \\
\hline \multicolumn{3}{|l|}{ Maternal age (years) } \\
\hline $10-29$ & $50(37)$ & $84(15)^{*}$ \\
\hline $30-39$ & $48(37)$ & $61(11)$ \\
\hline $40-80$ & $18(38)$ & $25(10)$ \\
\hline
\end{tabular}

Health conditions

Perception of health of the child reported by mother

$\begin{array}{lll}\text { Excellent } & 8(35)^{*} & 15(7)^{* *} \\ \text { Good } & 65(31) & 102(11) \\ \text { Poor } & 43(53) & 53(26)\end{array}$

Exposure to cigarette smoke

Current maternal smoking

$\begin{array}{lll}\text { No } & 101(38) & 153(13) \\ \text { Yes } & 14(33) & 16(9)\end{array}$

Presence of other smokers in the household

$\begin{array}{lll}\text { No } & 85(36) & 131(12) \\ \text { Yes } & 31(40) & 39(13)\end{array}$

Severity of asthma in the last 12 months

Number of exacerbations of wheezing

$\begin{array}{lll}\text { None } & 3(18) & 4(1)^{* *} \\ 1-3 & 75(34) & 91(31) \\ \geq 4 & 38(53) & 38(53)\end{array}$

Awakenings at night due to wheezing

Never woke up $12(40)$

$29(3)$
Table 2 (continued)

Characteristics

Children with Total sample of asthma $(n=312)$ children $(n=1,382)$

Less than one night per week $52(31) \quad 52(31)$

One or more nights per week 52 (45) 52 (45)

Difficulties in pronouncing two consecutive words during exacerbations

$\begin{array}{lll}\text { No } & 72(32)^{* *} & 88(7)^{* *} \\ \text { Yes } & 44(52) & 45(51)\end{array}$

Wheezing during or after exercising

$\begin{array}{lll}\text { No } & 64(32)^{*} & 117(9)^{* *} \\ \text { Yes } & 52(46) & 53(39) \\ \text { Visits to the doctor } & & \\ \text { None } & 44(34) & 73(7)^{* *} \\ 1-3 & 52(37) & 62(26) \\ \geq 4 & 19(44) & 20(41)\end{array}$

Visits to emergency services

$\begin{array}{lll}\text { None } & 105(36) & 145(11)^{*} \\ \text { One or more } & 11(52) & 11(33) \\ \text { Hospitalizations } & & \\ \text { None } & 74(32)^{*} & 114(9)^{* *} \\ \text { One or more } & 42(51) & 42(42)\end{array}$

$* P<0.05 ; * * P<0.001$

cantly more frequent in children who met certain characteristics related to the severity of asthma in the last 12 months. In Table 4, characteristics of children who were categorized as having severe asthma $(n=110 ; 35.3 \%)$ compared with those with nonsevere asthma $(n=202 ; 64.7 \%)$ are presented. Social and demographic differences were not observed between the two groups, but as expected the severe cases present a great frequency of severe symptoms and more frequent use of systemic corticosteroids.

\section{Discussion}

In this population-based study conducted among children living in poor neighborhoods from a large urban center in Brazil, a significant underuse of long-term control medications was found among those reported with asthma. In addition, $62.8 \%$ of the 312 children classified as asthmatic reported no use of any specific medication. Studies show that underuse of medication by certain children results mainly from their families' low socioeconomic level, thus hindering drug acquisition; characteristics of the health system; and professional practices $[7,20]$.

In Brazil, asthma is responsible for around 350,000 hospitalizations annually and represents the fourth cause of hospitalizations (2.3\% of the total) in the SUS (Unified Health System) and the third cause of hospitalizations among children and 

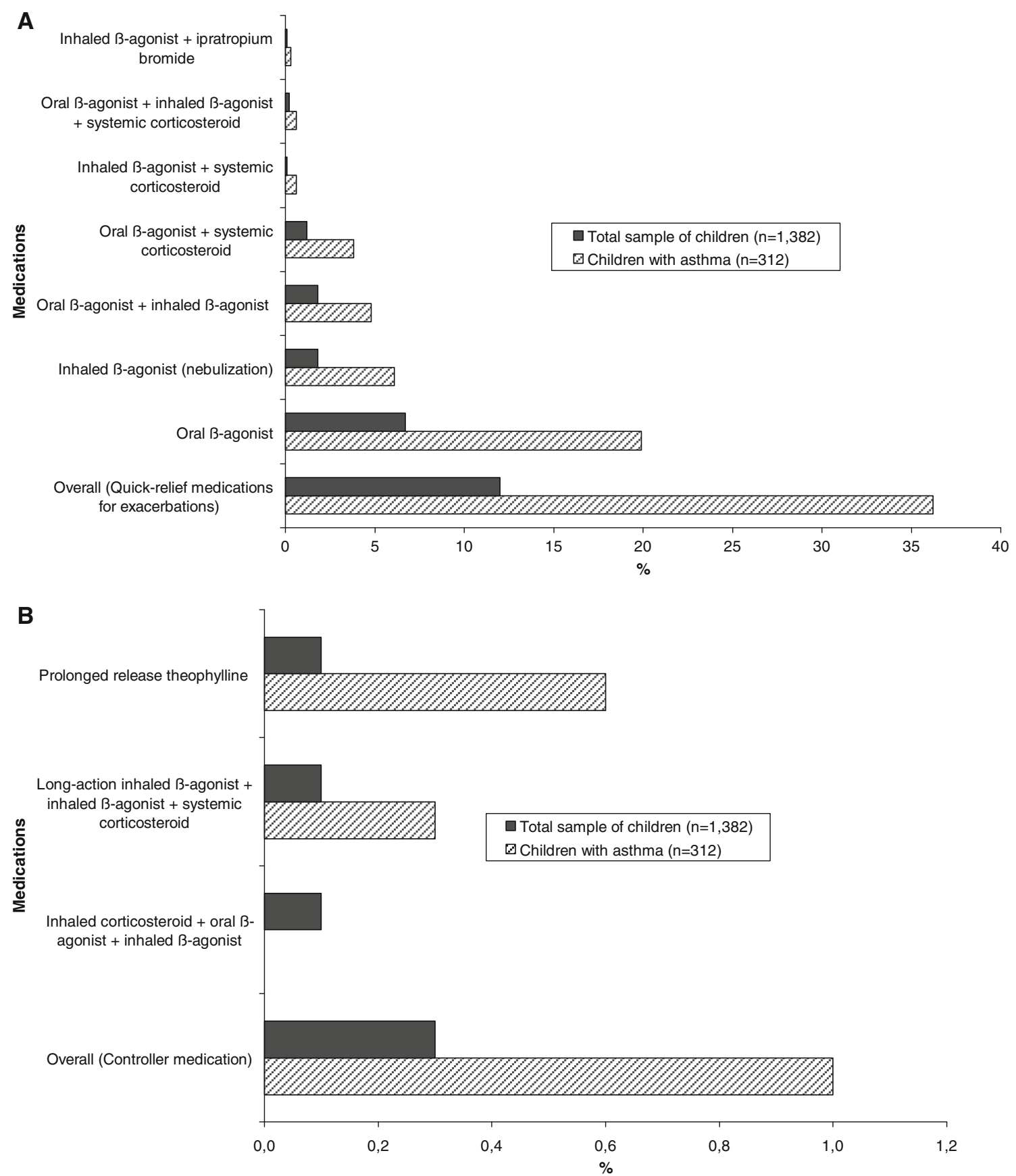

Fig. 1a, b Use of medications for asthma in monotherapy or in combination, in the last 12 months, among children in Salvador, Brazil. a Quick-relief medications for exacerbations, $\mathbf{b}$ controller medication

young adults. In 1996, SUS spent US\$43 million on hospitalizations due to asthma, $2.8 \%$ of the total annual spending and the third highest value spent on a specific disease [21-23].

Only $37 \%$ of asthmatic children had used medication for asthma in the 12 months prior to the survey. The most frequently used medicines by pharmacological group were, in decreasing order: oral $\beta$-agonists, inhaled $\beta$-agonists, and systemic corticosteroids. The distribution by age showed a more frequent use of inhaled $\beta$-agonists by older children and of systemic corticosteroids by younger ones. This is probably a result of the difficulties in teaching younger children how to use an inhaler, according to similar findings among German asthmatic children [24]. Of the asthmatic children, $12.7 \%$ had used systemic corticosteroids alone or in association with other anti-asthmatic medications. However, this group of drugs is not recommended for asthma treatment, due to an increased risk of bone fractures in children even when used for short periods of time $[25,26]$. 
Table 3 Type of asthma medication used by children with reported wheezing in a population-based sample from an urban center in Brazil

\begin{tabular}{|c|c|c|c|c|c|}
\hline & Numbers & Oral ß-agonists (\%) & Inhaled $\beta$-agonists $(\%)$ & Systemic corticosteroids $(\%)$ & No medicine $(\%)$ \\
\hline Overall & 312 & & & & \\
\hline \multicolumn{6}{|l|}{ Sex } \\
\hline Male & 171 & 27.5 & 11.7 & 7.0 & 57.3 \\
\hline Female & 141 & 31.2 & 14.2 & 3.5 & 56.7 \\
\hline \multicolumn{6}{|l|}{ Age (years) } \\
\hline $4-5$ & 98 & 26.5 & 14.3 & 8.2 & 55.1 \\
\hline 6 & 72 & 33.3 & 12.5 & 2.8 & 55.6 \\
\hline $7-8$ & 89 & 28.1 & 10.1 & 4.5 & 62.9 \\
\hline $9-11$ & 53 & 30.2 & 15.1 & 5.7 & 52.8 \\
\hline \multicolumn{6}{|l|}{ Maternal ethnicity } \\
\hline White & 27 & 33.3 & 22.2 & 7.4 & 51.8 \\
\hline Black & 285 & 28.8 & 11.9 & 5.3 & 42.1 \\
\hline \multicolumn{6}{|c|}{ Monthly household income (minimum wages) } \\
\hline$<1 \times \mathrm{MW}$ & 175 & 30.9 & $8.6^{*}$ & $2.3 *$ & 41.1 \\
\hline $1-5 \times \mathrm{MW}$ & 137 & 27.0 & 18.3 & 9.5 & 45.3 \\
\hline \multicolumn{6}{|c|}{ Indicators of severity of asthma in the last 12 months } \\
\hline \multicolumn{6}{|c|}{ Number of exacerbations of wheezing } \\
\hline None & 17 & $17.7^{*}$ & 5.9 & 0.0 & $82.4^{*}$ \\
\hline $1-3$ & 223 & 25.1 & 13.5 & 4.5 & 59.2 \\
\hline$\geq 4$ & 72 & 44.4 & 12.5 & 9.7 & 44.4 \\
\hline \multicolumn{6}{|c|}{ Awakenings at night due to wheezing } \\
\hline Never woke up & 30 & 30.0 & 16.7 & 3.3 & 56.7 \\
\hline Less than one night per week & 167 & 24.6 & 9.6 & 4.8 & 62.3 \\
\hline One or more nights per week & 115 & 35.7 & 16.5 & 7.0 & 49.6 \\
\hline \multicolumn{6}{|c|}{ Difficulty in pronouncing two consecutive words during exacerbations } \\
\hline No & 227 & $23.8^{*}$ & 11.9 & 4.4 & $61.2^{*}$ \\
\hline Yes & 85 & 43.5 & 15.3 & 8.2 & 45.9 \\
\hline \multicolumn{6}{|c|}{ Wheezing during or after exercising } \\
\hline No & 198 & $23.7^{*}$ & 12.1 & $2.5^{*}$ & 60.6 \\
\hline Yes & 114 & 38.6 & 14.0 & 10.5 & 50.9 \\
\hline \multicolumn{6}{|l|}{ Visits to the doctor } \\
\hline None & 129 & 29.5 & $8.5^{*}$ & 4.7 & 58.9 \\
\hline $1-3$ & 139 & 28.1 & 13.7 & 6.5 & 56.8 \\
\hline$\geq 4$ & 43 & 30.2 & 23.3 & 4.7 & 53.5 \\
\hline \multicolumn{6}{|l|}{ Visits to emergency services } \\
\hline None & 291 & 28.2 & 12.7 & 5.2 & 57.7 \\
\hline One or more & 21 & 42.9 & 14.3 & 9.5 & 47.6 \\
\hline \multicolumn{6}{|l|}{ Hospitalizations } \\
\hline None & 229 & $24.9^{*}$ & 11.4 & $2.2 *$ & $60.7^{*}$ \\
\hline One or more & 83 & 41.0 & 16.9 & 14.5 & 47.0 \\
\hline
\end{tabular}

$* P<0.05$

In this studied population, it has already been shown that the use of medicine, in general, is irrational for some pharmacological groups, in particular antibiotics and analgesics/antipyretics [27]. In the present study we showed that the patterns of use of medications for asthma are in great divergence with the recommendations established in guidelines that emphasize the need to use daily preventive anti-inflammatory drugs in children with asthma, be it mild, moderate, or severe [28]. Inhaled corticosteroids, the main pharmacological choice for control of this disease, were reported to have been used by only one child in this population. Other studies conducted in Brazil, although 
Table 4 Characteristics of children classified as having severe asthma compared with children with nonsevere asthma

\begin{tabular}{|c|c|c|c|c|}
\hline Characteristics & Number & $\begin{array}{l}\text { Severe asthma } \\
(n=110)(\%)\end{array}$ & $\begin{array}{l}\text { Nonsevere asthma } \\
(n=202)(\%)\end{array}$ & $P$-value \\
\hline Black mother & 285 & 88.2 & 93.1 & 0.142 \\
\hline Male & 171 & 59.1 & 52.5 & 0.262 \\
\hline $7-8$ years of age & 89 & 35.5 & 24.8 & 0.174 \\
\hline Household income less than minimum wage & 175 & 57.3 & 55.4 & 0.756 \\
\hline \multicolumn{5}{|l|}{ Severity of asthma in the last 12 months } \\
\hline $1-3$ exacerbations of wheezing & 223 & 65.5 & 74.8 & 0.012 \\
\hline $\begin{array}{l}\text { Less than one awakening at night } \\
\text { per week due to wheezing }\end{array}$ & 167 & 53.6 & 53.5 & 0.313 \\
\hline $\begin{array}{l}\text { Difficulty in pronouncing two consecutive } \\
\text { words during exacerbations }\end{array}$ & 85 & 44.6 & 17.8 & $<0.001$ \\
\hline Wheezing during or after exercising & 114 & 49.1 & 29.7 & 0.001 \\
\hline One or more visits to the doctor & 182 & 68.8 & 53.0 & 0.007 \\
\hline Visits to the emergency room & 21 & 10.9 & 4.5 & 0.030 \\
\hline \multicolumn{5}{|l|}{ Use of corticosteroids in the last 12 months } \\
\hline Systemic & 17 & 12.7 & 1.5 & $<0.001$ \\
\hline Inhaled & 1 & 0.9 & 0 & \\
\hline
\end{tabular}

focused on children cared for in health units, found frequencies of use of inhaled corticosteroids between 2 and $6 \%[18,29]$.

The reasons for underuse of inhaled corticosteroids in our context and the fact that well established recommendations are not followed reflect flaws in public health policies aimed at asthma, including the complete absence of strategies to increase prescribers' adherence to the asthma program recommendations, drug availability and affordability flaws, and lack of continuing education for families $[6,17]$. Inhaled corticosteroids are listed by the World Health Organization as essential medications, but they cost more than what low-income families can afford, thus emphasizing the need for these to be available in SUS primary health care units through the establishment of a broad public program for asthma control [29].

There were no significant associations between overall use of asthma medication and monthly household income, a result that is similar to those observed in other studies [24, 30]. However, inhaled $\beta$-agonists and systemic corticosteroids were used more frequently in children whose monthly household income was higher than the minimum wage. A similar finding was observed in a study among asthmatic German children where the use of systemic corticosteroids was more frequent in the richest ones [24]. In a study performed with a group of low-income asthmatic children in New York City, it was observed that many families understood asthma as an episodic disease, thus giving priority to symptomatic rather than preventive therapies [31, 32].

Inadequate treatment of asthma leads to the frequent use of emergency services and hospitalizations due to exacerbations and leads to a higher risk of complications [33, 34]. For the low-income population in Brazil, the emergency room is often the access to health services. In the case of asthma, children visit the emergency room motivated by exacerbations of a disease that is not controlled properly [29]. The present study demonstrated this situation. None of the 21 asthmatic children who frequently visited the emergency rooms used long-term control medications for asthma (inhaled corticosteroids, antileukotrienes, or prolonged-release theophylline). Constant visits to emergency units, motivated by exacerbations of asthma, are the best indicator of inadequate treatment [33].

The low quality of care provided to children with asthma was best evidenced in this study by the fact that half of the children classified as having severe asthma had not used any class of medication against asthma in the last 12 months. Moreover, of the 312 children who had asthma, $83(28 \%)$ had had at least one episode of hospitalization in the last 12 months, and 51\% were treated only with quickrelief medication ( $41 \%$ oral $\beta$-agonist and $16.9 \%$ inhaled $\beta$-agonist). In population-based studies, the rates of hospitalizations for asthmatic patients represent the joint effect of the prevalence and severity of the disease and the quality of health care provided. Studies have shown that intervention with inhaled corticosteroids contributes to decreased morbidity and mortality [35, 36] and hospitalizations [21] due to asthma.

Childhood asthma was highly prevalent in the studied population in this low-income urban community setting in Brazil [13], but an overwhelming majority of asthmatic children did not use long-term medications for asthma, in particular inhaled corticosteroids, regardless of the severity of their disease. Brazil has a comprehensive health system [37], but this result points to deficiencies in recognizing this important pharmacological need for child care, and thereby the access of these children to a group of efficacious and 
low risk therapeutic medications is limited. The lack of access to proper treatment with inhaled corticosteroids has put children at risk through their use of systemic corticosteroids. They may have been well prescribed to treat exacerbations that could have been avoided with the use of inhaled corticosteroids, which have an insignificant rate of systemic side effects. But, for an asthma control program to be effective-in addition to ensuring the availability of adequate pharmacological treatments - the program must be integrated with public education aimed at asthma patients and all health professionals, rather than prescribers only.

Acknowledgments This study is part of the SCAALA programme (Social Change, Asthma and Allergy in Latin America), funded by The Welcome Trust, UK, Ref 072405/Z/03/Z. Complementary funds were received from the INCT/CNPq programme Ref 610011/2009-0.

\section{References}

1. Asher MI, Montefort S, Bjorksten B, Lai CK, Strachan DP, Weiland SK, Williams H, ISAAC Phase Three Study Group (2006) Worldwide time trends in the prevalence of symptoms of asthma, allergic rhinoconjunctivitis, and eczema in childhood: ISAAC Phases One and Three multicountry cross-sectional surveys. Lancet 368:733-743

2. Cooper PJ, Rodrigues LC, Cruz AA, Barreto ML (2009) Asthma in Latin America: a public heath challenge and research opportunity. Allergy 64:5-17

3. Sears MR (1997) Epidemiology of childhood asthma. Lancet 350:1015-1020

4. Bousquet J, Kiley J, Bateman ED, Viegi G, Khaltaev N, Cruz AA, Khaltaev N, Aït Khaled N, Baena-Cagnani CE, Barreto ML, Billo $\mathrm{N}$, Canonica GW, Carlsen K-H, Chavannes N, Chuchalin A, Drazen J, Fabbri LM, Gerbase MW, Humbert M, Joos G, Masjedi MR, Makino S, Rabe K, To T, Zhi L (2010) Prioritized research agenda for prevention and control of chronic respiratory diseases. Eur Respir J 36:995-1001

5. Cruz AA, Bateman ED, Bousquet J (2010) The social determinants of asthma. Eur Respir J 35:239-242

6. Eggleston PA, Malveaux FJ, Butz AM, Huss K, Thompson L, Kolodner K, Rand CS (1998) Medications used by children with asthma living in the inner city. Pediatrics 101:349-354

7. Halterman JS, Aligne CA, Auinger P, McBride JT, Szilagyi PG (2000) Inadequate therapy for asthma among children in the United States. Pediatrics 105:272-276

8. Blais R, Gregoire JP, Rouleau R, Cartier A, Bouchard J, Boulet LP (2001) Ambulatory use of inhaled beta(2)-agonists for the treatment of asthma in Quebec: a population-based utilization review. Chest 119:1316-1321

9. Sears MR, Taylor DR (1994) The beta 2-agonist controversy. Observations, explanations and relationship to asthma epidemiology. Drug Saf 11:259-283

10. Guerra S, Sherrill DL, Venker C, Ceccato CM, Halonen M, Martinez FD (2010) Morbidity and mortality associated with the restrictive spirometric pattern: a longitudinal study. Thorax 65:499-504

11. Halfon N, Newacheck PW (1993) Childhood asthma and poverty: differential impacts and utilization of health services. Pediatrics 91:56-61
12. Mak H, Johnston P, Abbey H, Talamo RC (1982) Prevalence of asthma and health service utilization of asthmatic children in an inner city. J Allergy Clin Immunol 70:367-372

13. Cunha SS, Pujades-Rodriguez M, Barreto ML, Genser B, Rodrigues LC (2007) Ecological study of socio-economic indicators and prevalence of asthma in schoolchildren in urban Brazil. BMC Public Health 7:205

14. Solé D, Vanna AT, Yamada E, Rizzo MC, Naspitz CK (1998) International Study of Asthma and Allergies in Childhood (ISAAC) written questionnaire: validation of the asthma component among Brazilian children. J Investig Allergol Clin Immunol 8:376382

15. Sole D, Wandalsen GF, Camelo-Nunes IC, Naspitz CK (2006) Prevalence of symptoms of asthma, rhinitis, and atopic eczema among Brazilian children and adolescents identified by the International Study of Asthma and Allergies in Childhood (ISAAC) - Phase 3. J Pediatr 82:341-346

16. Rosario Filho NA (1996) Bronchodilators in asthma: bypassing controversies. J Pediatr 72:281-286

17. Duarte MC, Camargos PA (1999) Use of prophylactic medication in persistent asthma. J Pediatr 75:456-462

18. Camargos PA, Profeta SC (2003) Use of asthma controller drugs at admission to a pediatric pulmonology outpatient clinic. J Pediatr 79:233-238

19. Barreto ML, Cunha SS, Alcântara-Neves N, Carvalho LP, Cruz AA, Stein RT, Genser B, Cooper PJ, Rodrigues LC (2006) Risk factors and immunological pathways for asthma and other allergic diseases in children: background and methodology of a longitudinal study in a large urban center in northeastern Brazil (Salvador-SCAALA study). BMC Pulm Med 6:15

20. Cerveri I, Zoia MC, Bugiani M, Corsico A, Carosso A, Piccioni P, Casali L, De Marco R (1997) Inadequate antiasthma drug use in the north of Italy. Eur Respir J 10:2761-2765

21. Souza-Machado C, Souza-Machado A, Franco R, Ponte EV, Barreto ML, Rodrigues LC, Bousquet J, Cruz AA (2010) Rapid reduction in hospitalisations after an intervention to manage severe asthma. Eur Respir J 35:515-521

22. Cruz AA, Bousquet PJ (2009) The unbearable cost of severe asthma in underprivileged populations. Allergy 64:319-321

23. Franco R, Nascimento HF, Cruz AA, Santos AC, Souza-Machado C, Ponte EV, Souza-Machado A, Rodrigues LC, Barreto ML (2009) The economic impact of severe asthma to low-income families. Allergy 64:478-483

24. Beimfohr C, Maziak W, von Mutius E, Hense HW, Leupold W, Hirsch T, Keil U, Weiland SK (2001) The use of anti-asthmatic drugs in children: results of a community-based survey in Germany. Pharmacoepidemiol Drug Saf 10:315-321

25. van Staa TP, Cooper C, Leufkens HG, Bishop N (2003) Children and the risk of fractures caused by oral corticosteroids. J Bone Miner Res 18:913-918

26. Ducharme FM, Chabot G, Polychronakos C, Glorieux F, Mazer B (2003) Safety profile of frequent short courses of oral glucocorticoids in acute pediatric asthma: impact on bone metabolism, bone density, and adrenal function. Pediatrics 111:376-383

27. Santos DB, Barreto ML, Coelho HL (2009) Drug use and associated factors in children living in poor areas. Rev Saude Publ 43:768-778

28. Bateman ED, Hurd SS, Barnes PJ, Bousquet J, Drazen JM, FitzGerald M, Gibson P, Ohta K, OByrne P, Pedersen SE, Pizzichini E, Sullivan SD, Wenzel SE, Zar HJ (2008) Global strategy for asthma management and prevention: GINA executive summary. Eur Respir J 31:143-178

29. Cabral AL, Carvalho WA, Chinen M, Barbiroto RM, Boueri FM, Martins MA (1998) Are International Asthma Guidelines effective 
for low-income Brazilian children with asthma? Eur Respir J 12:35-40

30. Strachan DP, Anderson HR, Limb ES, O'Neill A, Wells N (1994) A national survey of asthma prevalence, severity, and treatment in Great Britain. Arch Dis Child 70:174-178

31. Yoos HL, Kitzman H, Henderson C, McMullen A, Sidora-Arcoleo K, Halterman JS, Anson E (2007) The impact of the parental illness representation on disease management in childhood asthma. Nurs Res 56:167-174

32. Yoos HL, McMullen A, Bezek S, Hondorf C, Berry S, Herendeen N, MacMaster K, Schwartzberg ML (1997) An asthma management program for urban minority children. J Pediatr Health Care 11:66-74

33. Joseph CL, Havstad SL, Ownby DR, Johnson CC, Tilley BC (1998) Racial differences in emergency department use persist despite allergist visits and prescriptions filled for antiinflammatory medications. J Allergy Clin Immunol 101:484-490

34. Lasmar L, Goulart E, Sakurai E, Camargos P (2002) Risk factors for hospital admissions among asthmatic children and adolescents. Rev Saude Publ 36:409-419

35. Suissa S, Ernst P, Benayoun M, Cai B (2000) Low-dose inhaled corticosteroids and the prevention of death from asthma. N Engl J Med 343:332-336

36. Hirst C, Calingaert B, Stanford R, Castellsague J (2010) Use of long-acting beta-agonists and inhaled steroids in asthma: metaanalysis of observational studies. J Asthma 47:439-446

37. Paim J, Travassos C, Almeida C, Bahia L, Macinko J (2011) The Brazilian health system: history, advances, and challenges. Lancet 377:1778-1797 